\title{
MRI TEXTURE ANALYSIS OF SUBCHONDRAL BONE AT THE TIBIAL PLATEAU
}

\author{
DR JAMES W MACKAY ${ }^{1}$ \\ DR PHILIP J MURRAY ${ }^{1}$ \\ MR BAHMAN KASMAI ${ }^{1}$ \\ PROFESSOR GLYN JOHNSON ${ }^{1,2}$ \\ PROFESSOR SIMON T DONELL 2,3 \\ PROFESSOR ANDONI P TOMS ${ }^{1,2}$
}

\author{
MB BCHIR MA MRCP \\ MBBS \\ BSC BA MSC MIPEM \\ BA MSC PhD \\ BSC MBBS FRCS(Orth) MD \\ BSC MBBS FRCS FRCR PhD
}

${ }^{1}$ Department of Radiology, Norfolk \& Norwich University Hospital, Norwich, UK

${ }^{2}$ Norwich Medical School, University of East Anglia, Norwich, UK

${ }^{3}$ Department of Trauma \& Orthopaedics, Norfolk \& Norwich University Hospital, Norwich, UK

Corresponding author:

Tel:

Fax:

Email:
Dr James MacKay

Radiology Academy

Norfolk \& Norwich University Hospital

Colney Lane

Norwich

Norfolk

$\mathrm{NR}_{4} 7 \mathrm{UB}$

United Kingdom

$+441603286143$

$+441603286146$

james.mackay@nnuh.nhs.uk 


\section{ABSTRACT}

Purpose

To determine the feasibility of MRI texture analysis as a method of quantifying subchondral bone architecture in knee osteoarthritis (OA).

\section{Methods}

Asymptomatic subjects aged 20-30 (group 1, $\mathrm{n}=10$ ), symptomatic patients aged 40-50 (group 2, $\mathrm{n}=10$ ) and patients scheduled for knee replacement aged 55-85 (group $3, \mathrm{n}=10$ ) underwent high spatial resolution T1 weighted coronal $3 \mathrm{~T}$ knee MRI.

Regions of interest were created in the medial (MT) and lateral (LT) tibial subchondral bone from which 20 texture parameters were calculated. T2 mapping of the tibial cartilage was performed in groups $1 \& 2$. Mean parameter values were compared between groups using ANOVA. Linear discriminant analysis (LDA) was used to evaluate the ability of texture analysis to classify subjects correctly.

\section{Results}

Significant differences in $18 / 20$ and $12 / 20$ subchondral bone texture parameters were demonstrated between groups at the MT and LT respectively. There was no significant difference in mean MT or LT cartilage $T 2$ values between group 1 and group 2 .

LDA demonstrated subject classification accuracy of $97 \%$ (95\% Cl 91-100\%).

\section{Conclusion}

MRI texture analysis of tibial subchondral bone may allow detection of alteration in subchondral bone architecture in OA. This has potential applications in understanding OA pathogenesis and assessing response to treatment. 


\section{KEY POINTS}

- Improved techniques to monitor OA disease progression and treatment response are desirable.

- Subchondral bone (SB) may play significant role in the development of OA.

- MRI texture analysis is a method of quantifying changes in SB architecture.

- Pilot study showed that this technique is feasible and reliable.

- Significant differences in SB texture were demonstrated between individuals with/without OA.

\section{KEY WORDS}

Osteoarthritis

Knee

MRI

Bone

Discriminant Analysis 


\section{INTRODUCTION}

The development of novel therapeutic approaches in osteoarthritis $(O A)$ is hampered by a limited ability to detect the earliest stages of disease[1]. This is important as it is individuals with early disease who are most likely to respond to targeted preventative or regenerative therapy, before irreversible changes have occurred.

Magnetic resonance (MR) imaging is an established method for OA diagnosis and monitoring disease progression. The importance of subchondral bone (SB) in the pathogenesis of OA is well established[2]. To date, much MR imaging research in OA has been focussed on articular cartilage where multiple quantitative parameters are available[3]. For example, T2 mapping is able to demonstrate increased water content of articular cartilage associated with changes in collagen content and has demonstrated good correlation with the degree of histological degeneration[4]. However, it has been suggested that changes in SB may occur in parallel to or even predate cartilage $\operatorname{loss}[5,6]$, and dynamic changes in the SB have been demonstrated in response to treatment[7]. Therefore, biomarkers of early changes in SB architecture may be helpful in the early detection and monitoring of $\mathrm{OA}$ as well as evaluation of treatment response.

SB architecture has been evaluated using radiography, employing techniques such as fractal signature analysis $[8,9]$, bone density measurement $[10]$ and trabecular microstructural analysis[11]. Such techniques have had some success in demonstrating associations between changes in SB structure/density with onset and progression of OA. However, radiographic evaluation has the disadvantage, when compared to MR, of lack of information on other joint structures involved in the disease process.

MR quantification of SB architecture to date has focused on trabecular microstructural analysis [1215], although alternatives including semiquantitative grading of subchondral sclerosis [16] and MR signal heterogeneity analysis [17] have been attempted. While initial results from these techniques 
have been promising, a number of issues remain. For example, the gradient echo sequences used to achieve the required spatial resolution for trabecular microstructural analysis within a feasible timeframe in vivo are prone to artefact, and many of the structural parameters calculated are highly sensitive to changes in acquisition parameters, therefore limiting reproducibility[14, 18].

Textural analysis (TA) offers an alternative method for MR quantification of SB architecture distinct to conventional trabecular microstructural analysis. This is a statistical image analysis technique aiming to quantify the texture of an image based on pixel signal intensity distributions and the relationships between values of neighbouring pixels. Its value lies in detecting subtle alterations in appearance of a tissue early in the pathological process, invisible to the naked eye. TA has proven of value in several radiological studies, including colorectal cancer prognosis, structural changes in myoclonic epilepsy and differentiation of types of gastric tumour [19-22]. It has also demonstrated utility in the musculoskeletal system, for instance in evaluating articular cartilage at the knee and bone structure at the femoral neck[23, 24]. TA of trabecular bone has demonstrated good correlation with conventional structural bone parameters $[25,26]$.

However, TA has not been used to date as a method of assessing subchondral bone architecture at the knee. It may offer potential as a biomarker of early OA suitable for use in further longitudinal studies.

The objective of this study was to determine the feasibility of MR TA as a method of quantifying subchondral bone architecture at the tibial plateau. 


\section{MATERIALS \& METHODS}

Ethical approval for the study was obtained from the Local Research Ethics Committee. All subjects provided written, informed consent. This was a prospective, observational feasibility study, carried out at our institution between February and August 2014.

\section{PARTICIPANTS}

Three groups of 10 participants were recruited. Group 1 contained 10 asymptomatic volunteers aged 20-30 who had a normal BMI (body mass index). Group 2 contained 10 participants aged between 40-50 who had been referred to the Orthopaedic service at our institution with nontraumatic knee pain, and had knee radiographs demonstrating no significant OA (KellgrenLawrence grade $<2$ )[27]. Group 3 contained 10 participants aged $55-85$ who were scheduled to undergo total knee replacement (TKR).

These participant groups were designed to provide a cross-sectional sample of various stages of OA, including normal/no OA (group 1), at risk of OA/possible early OA (group 2) and established OA (group 3).

Participants were excluded if there was a history of significant lower limb injury or lower limb surgery, inflammatory arthritis, haematological malignancy, bone metastases, metabolic bone disease or if there was a contraindication to MR imaging.

All participants had their height and weight recorded at the time of their MR examination and completed an Oxford Knee Score questionnaire to assess severity of symptoms[28]. 


\section{RADIOGRAPHS}

Participants in groups 2 and 3 underwent weight-bearing AP and lateral radiographs of the symptomatic knee prior to MR imaging. The Kellgren-Lawrence grading of OA was assessed by two independent observers, both Radiology residents with 3 years' experience (JM \& PM), with any disagreement resolved by consensus with a senior reader, a musculoskeletal radiologist with 12 years' experience (AT). Participants in group 2 were excluded if there was evidence of OA (KellgrenLawrence $\geq 2$ ).

\section{MR IMAGING}

All participants underwent MR of the knee on a GE 3.0T wide-bore platform (GE Healthcare, Amersham, UK) using an 8 channel high-definition knee coil (GE WD 750). The study MR protocol featured a sagittal intermediate-weighted sequence with spectral fat saturation (fatsat) to evaluate for bone marrow lesions (BML) or focal cartilage defects (FOV $15 \times 15.4 \mathrm{~cm}$, matrix $352 \times 288$, TR $3422 \mathrm{mSec}$, TE $48.31 \mathrm{mSec}$, number of excitations (NEX) 1, slice thickness $3 \mathrm{~mm}$ ), a coronal high resolution T1 weighted (T1w) sequence to permit optimal visualization of the SB (FOV $12 \times 12.3$, matrix 512 × 512, TR 593, TE 17.65, NEX 1, slice thickness $2.5 \mathrm{~mm}$ ), and a multi-echo T2 weighted sequence to allow cartilage T2 mapping, performed in the coronal plane to allow better comparison with subchondral bone values (FOV $12 \times 12.3 \mathrm{~cm}$, matrix $256 \times 192$, TR 800, TE 6.93/13.86/20.78/27.71/34.64/41.57/48.50/55.42, NEX 1, slice thickness 2.5 mm). A sample high resolution T1 weighted image from each group is shown in figure 1.

\section{CLINICAL MR ANALYSIS}

All MR studies were reviewed by a consultant musculoskeletal radiologist with 12 years' experience (AT). As the purpose of group 2 was to include individuals with possible early OA, any potential participants in group 2 with MR evidence of established OA - as defined for the purposes of this study by full thickness cartilage defects or BMLs - were excluded. We did not include ligament 
damage or meniscal pathology in our exclusion criteria as these are considered as predisposing factors for OA rather than features of established OA as such[29]. One potential group 2 subject was excluded due to a full thickness cartilage defect. The MR studies of group 1 participants were also reviewed to ensure that there was no structural abnormality.

\section{SAMPLE SIZE}

There were no reliable pilot data available for this study thus a formal sample size calculation was not performed. However, the numbers included are at least equal to those in similar previous studies evaluating novel imaging methods in $\mathrm{OA}[14,30]$.

\section{TEXTURE ANALYSIS}

Texture analysis was performed on the medial and lateral tibial SB using dedicated software (MazDa version 4.6)[31]. For this analysis, six high-resolution T1w coronal images through the central portion of the tibial plateau (as determined by cross referencing to sagittal and axial localizers) were selected for each subject. Regions of interest (ROI) were created to enclose the medial and lateral SB on each image. The ROI was defined superiorly by the osteochondral junction, inferiorly by the proximal tibial physeal scar, and medially/laterally by vertical lines drawn through the apex of the medial/lateral tibial spines and medial/lateral borders of the tibial plateau (figure 2).

Twenty texture parameters, listed in table 1, were extracted for each region of interest on each slice. Run-length matrix (RLM) parameters are calculated 4 times for each ROI (vertical, horizontal, $\left.45^{\circ}, 135^{\circ}\right)$ and grey-level co-occurrence matrix (GLCM) parameters are calculated 20 times for each ROI at a variety of pixel offsets. For the comparison of textural features between groups, the mean value of RLM and GLCM parameters was used for each ROI, giving a total of 20 parameters to be analysed. A more detailed description of the texture parameters calculated is provided by Haralick et al[32]. 
Region of interest creation was performed by two independent observers, both Radiology residents with 3 years' experience (JM \& PM). Reproducibility was assessed by constructing Bland-Altman plots and determining the mean bias and $95 \%$ limits of agreement for each calculated texture parameter[33].

\section{TEXTURE COMPARISON}

The distribution of textural features in each group was assessed using Q-Q plots to see if a normal distribution could be assumed for further testing.

The mean values of each textural parameter were then compared between groups using one-way ANOVA with post-hoc unpaired Student's $t$-tests where significant differences between the three groups were demonstrated. The Bonferroni method was used to account for multiplicity of testing. With 20 parameters compared between groups at both medial and lateral tibial plateau, a significant difference between the means was therefore defined by a p value of $<0.0025(0.05 / 20)$. We did not adjust for age, sex or BMI in this feasibility study as differences in these parameters between groups did not affect the primary research question.

\section{CARTILAGE ANALYSIS}

Cartilage T2 mapping was performed in groups 1 \& 2 using a GE workstation equipped with $T_{2}$ mapping capability (Functool, AW VolumeShare 5, GE Healthcare). This was to determine whether hypothesized differences in subchondral bone texture parameters were associated with quantitative differences in the overlying articular cartilage.

The medial and lateral tibial cartilage was segmented manually on the 6 coronal images corresponding to those used for textural analysis. The mean T2 relaxation time for the medial and lateral cartilage on each image was recorded. Most participants in group 3 had areas of full thickness cartilage loss therefore T2 mapping was not performed in this group. 
The mean medial and lateral cartilage T2 values were compared between groups 1 and 2 using an unpaired Student's $t$-test (following assessment for a normal distribution), with a significant difference between the means defined as a $p$ value of $<0.05$.

\section{LINEAR DISCRIMINANT ANALYSIS}

The ability of textural analysis to classify individual images and individual participants into the correct group was evaluated using linear discriminant analysis (LDA), a statistical method used in machine learning to determine the linear combination of features best able to classify a given set of data.

The most discriminating of the calculated textural features were selected using a combination of the Fisher coefficient (ratio of between-group variance to within-group variance) and the probability of classification error (POE)/absolute correlation coefficient (ACC) minimization method. A full description of these methods is provided by Szczypiński et al[31].

The textural features selected as most discriminating were used to perform linear discriminant analysis. The usefulness of LDA to classify images was assessed using the linear separability coefficient[34]. This has a value between $o$ and 1, with 1 representing perfect classification. The number of misclassified images and misclassified participants was calculated. A participant was defined as being misclassified if more than $2 / 6$ coronal images used for analysis were incorrectly classified.

The LDA was performed in duplicate using both medial and lateral tibial plateau datasets. 


\section{RESULTS}

\section{PARTICIPANTS}

Baseline characteristics of study participants are summarized in table 2.

\section{TEXTURE ANALYSIS}

At the medial tibial plateau, mean values of $18 / 20$ textural parameters were significantly different between the three groups. The variance of the ROI histogram and the run-length matrix (RLM) parameter grey-level non-uniformity (GLNU) demonstrated significant differences between all combinations of individual groups in post-hoc tests.

At the lateral tibial plateau, mean values of $12 / 20$ textural parameters were significantly different between the three groups. The RLM parameter GLNU demonstrated significant differences between all combinations of individual groups in post-hoc tests.

Results for all parameters are summarized in tables 3 and 4 and in figure 3 .

\section{INTER-OBSERVER RELIABILITY}

Results of Bland-Altman analysis with mean bias and $95 \%$ limits of agreement for each calculated texture parameter are demonstrated in table 5 , with selected Bland-Altman plots in figure 6 .

\section{CARTILAGE MAPPING}

There was no significant difference $(p=0.125)$ in mean cartilage $T_{2}$ values at the medial tibial plateau between groups 1 (mean, $95 \% \mathrm{Cl}=39.0 \mathrm{mSec}, 37.7-40.3)$ and $2(40.6 \mathrm{mSec}, 38.8-42.4)$ and no significant difference $(p=0.06)$ in mean cartilage $T 2$ value at the lateral tibial plateau between groups 1 (33.1 mSec, 32.0-34.2) and 2 (34.8 $\mathrm{mSec}, 33.6-36.0)$.

LINEAR DISCRIMINANT ANALYSIS 
Linear discriminant analysis demonstrated a linear separability coefficient of the data points into three groups of 0.76 using medial tibial plateau data and 0.78 using lateral tibial plateau data (figure 4). The linear separability coefficient assesses how well separated the data points belonging to each class are by the discriminant functions, with a value between $0-1(1=$ perfect)[34].

Medial tibial plateau data gave a slice classification accuracy of $154 / 180$ (86\%, 95\% Cl 80-91\%) and a subject classification accuracy of $29 / 30$ (97\%, 91-100\%). Lateral tibial plateau data also gave a slice classification accuracy of $154 / 180(86 \%, 80-91 \%)$ and a subject classification accuracy of $29 / 30$ (97\%, $91-100 \%)$. 


\section{DISCUSSION}

This study demonstrated a significant difference in the MR SB texture of the three groups.

Discriminant analysis using texture parameters was able to accurately classify subjects into the correct group. These results suggest that MR TA is a feasible method of quantifying SB architecture at the tibial plateau.

Most textural features were significantly different between the three groups. It is unsurprising that the majority of features were significantly different between groups 1 and 3 and groups 2 and 3, as the appearances of the SB of knees with significant OA are different to those without OA to the naked eye.

Of more importance are those textural parameters significantly different between groups 1 and 2 . Individuals in group 2 had no radiographic evidence of $\mathrm{OA}$ (Kellgren-Lawrence $<2$ ), no $B M L$, and no focal cartilage defects. Quantitative cartilage imaging with T2 mapping did not reveal any significant differences between the two groups, implying no significant difference in degree of histological cartilage degeneration[4]. Therefore, a significant difference in the SB texture of these two groups supports the hypothesis that alterations in SB architecture occur early in the OA disease process. The lack of significant difference in the mean $T_{2}$ values of the overlying articular cartilage suggests that these changes in the SB may be occurring prior to any cartilage degeneration, although longitudinal studies would be required to elucidate the exact series of events.

The spatial resolution required for reliable direct MR measurement of trabecular bone microstructural parameters can be difficult to achieve at commonly available field strengths $(\leq 3.0$ T) and within clinically feasible timeframes in vivo, particularly when there are a number of other joint structures to be imaged. Texture parameters calculated from clinically feasible lower resolution images have demonstrated excellent correlation with conventional structural parameters in several studies $[25,35]$. 
Each textural parameter measures a particular property of the arrangement of pixels within an ROI such as variance, contrast and branching. Conceptually a number of these parameters have correlates with trabecular changes that are known to occur in OA. Such changes are likely to be visible to the naked eye in advanced OA. However, it is possible that in early disease subtle structural alterations are taking place in the SB such as increased trabecular discontinuity, thickening and disorganisation, all abnormalities described in $\mathrm{OA}[36]$. Changes in each class of texture parameter may reflect these alterations.

For example, a generalized increase in tissue disorganisation is likely to manifest as increased heterogeneity within the ROI. This would be reflected by changes in histogram-based features such as variance, which characterise the overall distribution of pixel values within the ROI. Loss of the fine linear pattern of the subchondral trabeculae with alternating areas of high and low signal would affect gradient based features which measure the spatial variation of grey values across an image and depend on the smoothness of transition from areas of high to low signal intensity and vice versa. Increased trabecular discontinuity would affect RLM parameters such as GLNU, which are calculated based on the number of pixels of a given grey-value occurring in runs (i.e. having adjacent pixels of the same MR signal intensity) within the ROI. A generalized increase in the number of areas of homogeneous low signal intensity (reflecting subchondral sclerosis) would affect GLCM parameters such as contrast, which are dependent on the spatial distribution of pixel values within the ROI.

Linear discriminant analysis proved successful at classifying subjects into the correct group, with a subject classification accuracy of $97 \%$. Such a classification method may have the potential to stratify risk of OA progression (figure 5). At the medial tibial plateau, it can be seen that some of the group 2 data points are closer to the group 1 data points (zone 1), whereas some are closer to those of group 3 (zone 2). It could be that individuals with data points in zone 2 have more unfavourable SB architecture and are therefore at increased risk of progression to frank OA. Should this method 
be validated in larger, longitudinal studies, LDA could be used to identify individuals most likely to benefit from targeted preventative therapy.

The results of this study should be taken in the context of a wider body of work emphasizing the importance of SB in OA pathogenesis and progression. Radiographic indices of subchondral bone integrity have previously been associated with increased cartilage thickness[10] and decreased risk of progressive joint space loss[9]. Previous MR studies have demonstrated alterations in microstructural trabecular morphometry measurements between volunteers and individuals with $\mathrm{OA}[13,14]$, and that such measurements correlate well with severity of $\mathrm{OA}[15]$. Proposed mechanisms of alteration in SB architecture include entry of inflammatory infiltrates via vascular channels in the SB[37] and increased deposition of subchondral marrow lipids[38].

Subchondral bone is a potential therapeutic target in OA. The dynamic nature of bone is well established. Physical therapy interventions have been shown to cause increased bone formation in patients mild $\mathrm{OA}[7]$. Microfracture techniques, which are widely used in the repair of osteochondral injury, are based on the stimulation of SB to regenerate the overlying cartilage[39]. Given its potential ability to depict subtle early changes as demonstrated in this study, TA of SB may offer a way to evaluate dynamic changes in SB architecture with OA treatment.

This study has demonstrated the feasibility of TA as a method of quantifying SB architecture. Our method was reliable with Bland-Altman analyses demonstrating $95 \%$ limits of agreement for most parameters that were substantially less than the magnitude of the differences between groups. Previous studies using TA have demonstrated similarly excellent reproducibility[24]. Parameters with wider $95 \%$ limits of agreement are likely to be more sensitive to small changes in ROI position. Moreover, some parameters demonstrated a funnelling effect, with more disagreement at higher values (figure 6). Higher values for most texture parameters were found in group 3 (advanced OA). The irregularity of the SB contour in these individuals may have led to increased variation in ROI placement between observers. 
This study had several limitations. Our method is based on MR signal, which - unlike attenuation values in CT - is dependent on acquisition parameters and may vary across MR platforms, limiting the generalizability of our results. However, a previous TA study looking at tissues around the knee found that whilst there was some variability of texture parameters between MR platforms the ability to distinguish between different tissue types remained[40]. Nevertheless future validation of this technique across platforms remains important.

Previous studies evaluating SB have used $3 \mathrm{D}$ isotropic gradient echo sequences in order to allow calculation of conventional trabecular microstructural parameters $[14,15]$. Our study used 2D high spatial resolution T1 weighted sequence designed to maximise signal-to-noise ratio due to increased slice thickness compared with 3D sequences. This does not permit calculation of volumetric data. However, TA of such 2D images has previously demonstrated good correlation with conventional structural parameters[24, 26], suggesting that textural parameters derived from these images can indeed provide a good assessment of bone architecture.

There was intentional variation in participant age between the three study groups in this study. The relative contribution of normal ageing versus the OA disease process to the SB changes demonstrated is therefore uncertain. However, this did not affect the primary research question which was to determine the feasibility of MR TA as a method of quantifying SB architecture at the tibial plateau and as a tool for identifying early subchondral changes. The results of this study suggest that it is and the heterogeneity of participant groups does not affect this outcome. Moreover, the effect of normal ageing in isolation on subchondral bone architecture does not offer an explanation as to why more textural parameters were significantly different between groups at the medial tibial plateau (18/20 parameters) than at the lateral tibial plateau (12/20 parameters). This may reflect the fact that medial compartment $O A$ is significantly more common than lateral compartment $\mathrm{OA}[41]$, with more $\mathrm{SB}$ architectural alteration having occurred in this compartment in individuals who have established OA or may be developing early OA. 
We performed analysis only of the tibial SB and articular cartilage and did not include the femur or patella. This was due to the flatter articular surface of the tibia facilitating easier and more reproducible ROI placement. In addition, previous studies of subchondral bone changes in OA have used the tibia for initial assessment $[42,43]$. Future studies could extend our methodology to the femur and patella.

This was a pilot study aiming to test the feasibility of TA to quantify SB architecture rather than determining the series of events in OA pathogenesis. Future studies using the method could involve a longitudinal element to evaluate this further, and also determine the sensitivity to change of the method following an intervention. 


\section{REFERENCES}

1. Guermazi A, Roemer FW, Felson DT, Brandt KD (2013) Motion for debate: osteoarthritis clinical trials have not identified efficacious therapies because traditional imaging outcome measures are inadequate. Arthritis Rheum 65:2748-2758.

2. Radin EL, Rose RM (1986) Role of subchondral bone in the initiation and progression of cartilage damage. Clin Orthop Relat Res 213: 34-40.

3. Choi J-A, Gold GE (2011) MR imaging of articular cartilage physiology. Magn Reson Imaging Clin N Am 19:249-282.

4. Dunn TC, Lu Y, Jin H, et al. (2004) T2 Relaxation Time of Cartilage at MR Imaging: Comparison with Severity of Knee Osteoarthritis. Radiology 232:592-598.

5. Mansell JP, Collins C, Bailey AJ (2007) Bone, not cartilage, should be the major focus in osteoarthritis. Nat Rev Rheumatol 3:306-307.

6. Muraoka T, Hagino H, Okano T, et al. (2007) Role of subchondral bone in osteoarthritis development: A comparative study of two strains of guinea pigs with and without spontaneously occurring osteoarthritis. Arthritis Rheum 56:3366-3374.

7. Multanen J, Nieminen MT, Häkkinen A, et al. (2014) Effects of high-impact training on bone and articular cartilage: 12-month randomized controlled quantitative MRI study. J Bone Miner Res 29:192-201.

8. Messent EA, Ward RJ, Tonkin CJ, Buckland-Wright C (2005) Cancellous bone differences between knees with early, definite and advanced joint space loss; a comparative quantitative macroradiographic study. Osteoarthritis Cartilage 13:39-47.

9. Kraus VB, Feng S, Wang S, et al. (2013) Subchondral Bone Trabecular Integrity Predicts and Changes Concurrently With Radiographic and Magnetic Resonance Imaging-Determined Knee Osteoarthritis Progression. Arthritis Rheum 65:1812-1821.

10. Cao Y, Stannus OP, Aitken D, et al. (2013) Cross-sectional and longitudinal associations between systemic, subchondral bone mineral density and knee cartilage thickness in older adults with or without radiographic osteoarthritis. Ann Rheum Dis 73: 2003-2009

11. Wong AKO, Beattie KA, Emond PD, et al. (2009) Quantitative analysis of subchondral sclerosis of the tibia by bone texture parameters in knee radiographs: site-specific relationships with joint space width. Osteoarthritis Cartilage 17:1453-1460.

12. Blumenkrantz G, Lindsey CT, Dunn TC, et al. (2004) A pilot, two-year longitudinal study of the interrelationship between trabecular bone and articular cartilage in the osteoarthritic knee. Osteoarthritis Cartilage 12:997-1005.

13. Chang G, Xia D, Chen C, et al. (2015) 7T MRI detects deterioration in subchondral bone microarchitecture in subjects with mild knee osteoarthritis as compared with healthy controls. J Magn Reson Imaging 41:1311-1317

14. Schneider E, Lo GH, Sloane G, et al. (2011) Magnetic resonance imaging evaluation of weightbearing subchondral trabecular bone in the knee. Skeletal Radiol 40:95-103. 
15. Lo GH, Tassinari AM, Driban JB, et al. (2012) Cross-sectional DXA and MR measures of tibial periarticular bone associate with radiographic knee osteoarthritis severity. Osteoarthritis Cartilage 20:686-693.

16. Crema MD, Cibere J, Sayre EC, et al. The relationship between subchondral sclerosis detected with MRI and cartilage loss in a cohort of subjects with knee pain: the knee osteoarthritis progression (KOAP) study. Osteoarthritis Cartilage 22: 540-546

17. MacKay JW, Godley KC, Toms AP (2014) MRI signal-based quantification of subchondral bone at the tibial plateau: a population study. Skeletal Radiol 43:1567-1575.

18. Majumdar S, Newitt D, Jergas M, et al. (1995) Evaluation of technical factors affecting the quantification of trabecular bone structure using magnetic resonance imaging. Bone 17:417-430.

19. Ng F, Ganeshan B, Kozarski R, et al. (2013) Assessment of Primary Colorectal Cancer Heterogeneity by Using Whole-Tumor Texture Analysis: Contrast-enhanced CT Texture as a Biomarker of 5-year Survival. Radiology 266:177-184.

20. Suoranta S, Holli-Helenius K, Koskenkorva P, et al. (2013) 3D Texture Analysis Reveals Imperceptible MRI Textural Alterations in the Thalamus and Putamen in Progressive Myoclonic Epilepsy Type 1, EPM1. PLoS ONE 8:e69905.

21. Ba-Ssalamah A, Muin D, Schernthaner R, et al. (2013) Texture-based classification of different gastric tumors at contrast-enhanced CT. Eur J Radiol 82:e537-543.

22. Castellano G, Bonilha L, Li LM, Cendes F (2004) Texture analysis of medical images. Clin Radiol 59:1061-1069.

23. Blumenkrantz G, Stahl R, Carballido-Gamio J, et al. (2008) The feasibility of characterizing the spatial distribution of cartilage T2 using texture analysis. Osteoarthritis Cartilage 16:584590.

24. Harrison LCV, Nikander R, Sikiö M, et al. (2011) MRI texture analysis of femoral neck: Detection of exercise load-associated differences in trabecular bone. J Magn Reson Imaging 34:1359-1366.

25. Showalter C, Clymer BD, Richmond B, Powell K (2006) Three-dimensional texture analysis of cancellous bone cores evaluated at clinical CT resolutions. Osteoporos Int 17:259-266.

26. Tameem HZ, Selva LE, Sinha US (2007) Texture measure from low resolution MR images to determine trabecular bone integrity in osteoporosis. Conf Proc Annu Int Conf IEEE Eng Med Biol 2007:2027-2030.

27. Kellgren JH, Lawrence JS (1957) Radiological assessment of osteo-arthrosis. Ann Rheum Dis 16:494-502.

28. Dawson J, Fitzpatrick R, Murray D, Carr A (1998) Questionnaire on the perceptions of patients about total knee replacement. J Bone Joint Surg Br 8o-B:63-69.

29. Shapiro LM, McWalter EJ, Son M-S, et al. (2014) Mechanisms of osteoarthritis in the knee: MR imaging appearance. J Magn Reson Imaging 39:1346-1356. 
30. Lowitz T, Museyko O, Bousson V, et al. (2013) Bone marrow lesions identified by MRI in knee osteoarthritis are associated with locally increased bone mineral density measured by QCT. Osteoarthr Cartil OARS Osteoarthr Res Soc 21:957-964.

31. Szczypiński PM, Strzelecki M, Materka A, Klepaczko A (2009) MaZda--a software package for image texture analysis. Comput Methods Programs Biomed 94:66-76.

32. Haralick R, Shanmugam K, I Dinstein (1973) Textural features for image classification. IEEE Trans Syst Man Cybern 3:610-621.

33. Bland JM, Altman DG (1986) Statistical methods for assessing agreement between two methods of clinical measurement. Lancet 1:307-310.

34. Mao J, Jain AK (1995) Artificial neural networks for feature extraction and multivariate data projection. IEEE Trans Neural Netw 6:296-317.

35. Link TM, Majumdar S, Lin JC, et al. (1998) Assessment of trabecular structure using high resolution CT images and texture analysis. J Comput Assist Tomogr 22:15-24.

36. Bobinac D, Spanjol J, Zoricic S, Maric I (2003) Changes in articular cartilage and subchondral bone histomorphometry in osteoarthritic knee joints in humans. Bone 32:284-290.

37. Binks DA, Gravallese EM, Bergin D, et al. (2015) Role of vascular channels as a novel mechanism for subchondral bone damage at cruciate ligament entheses in osteoarthritis and inflammatory arthritis. Ann Rheum Dis 74: 196-203

38. Wang L, Salibi N, Chang G, et al. (2014) Evaluation of Subchondral Bone Marrow Lipids of Acute Anterior Cruciate Ligament (ACL)-Injured Patients at 3 T. Acad Radiol 21: 758-766

39. Chen $\mathrm{H}$, Chevrier A, Hoemann CD, et al. (2011) Characterization of subchondral bone repair for marrow-stimulated chondral defects and its relationship to articular cartilage resurfacing. Am J Sports Med 39:1731-1740.

40. Mayerhoefer ME, Breitenseher MJ, Kramer J, et al. (2005) Texture analysis for tissue discrimination on T1-weighted MR images of the knee joint in a multicenter study: Transferability of texture features and comparison of feature selection methods and classifiers. J Magn Reson Imaging 22:674-680.

41. Wise BL, Niu J, Yang M, et al. (2012) Patterns of Compartment Involvement in Tibiofemoral Osteoarthritis in Men and Women and in Caucasians and African Americans: the Multicenter Osteoarthritis Study. Arthritis Care Res 64:847-852.

42. Driban JB, Barbe MF, Amin M, et al. (2014) Validation of quantitative magnetic resonance imaging-based apparent bone volume fraction in peri-articular tibial bone of cadaveric knees. BMC Musculoskelet Disord 15:143.

43. Bruyere O, Dardenne $C$, Lejeune $E$, et al. (2003) Subchondral tibial bone mineral density predicts future joint space narrowing at the medial femoro-tibial compartment in patients with knee osteoarthritis. Bone 32:541-545. 


\section{FIGURE LEGENDS}

Figure 1. Coronal T1 weighted images of the knees of (A) a 27 year old male (group 1 ), (B) a 45 year old male (group 2) and (C) a 67 year old male (group 3).

Figure 2. Region of interest creation in the medial tibial SB using MazDa textural analysis programme. The ROI boundary (white dashed line) was defined medially and laterally by vertical lines through the apex of the medial/lateral tibial spines and the medial/lateral edges of the tibial plateau, superiorly by the osteochondral junction and inferiorly by the proximal tibial physeal scar. Figure 3. Comparison of texture features variance (histogram parameter), gradient mean (gradient parameter), GLNU (RLM parameter) and contrast (GLCM parameter) between groups 1, 2 and 3 at the medial and lateral tibial plateau. Error bars represent standard errors of the means.

Figure 4. Linear discriminant analysis plots showing good linear separability of the data points for medial tibial plateau and lateral tibial plateau. Discriminant functions are linear combinations of the original textural parameters. Red diamonds represent individual ROIs from group 1; green crosses group 2, blue circles - group 3.

Figure 5. Schematic diagram illustrating distribution of data points for group 1 (red circle), group 2 (green circle) and group 3 (blue circle) at the medial tibial plateau. Some data points in group 2 overlap with those of group 1 (marked as zone 1), and some overlap with group 3 (zone 2). Individuals with data points in zone 2 may be at increased risk of progression to OA.

Figure 6. Bland-Altman plots illustrating inter-observer agreement for selected texture features. 
TABLE 1

Summary of textural parameters calculated

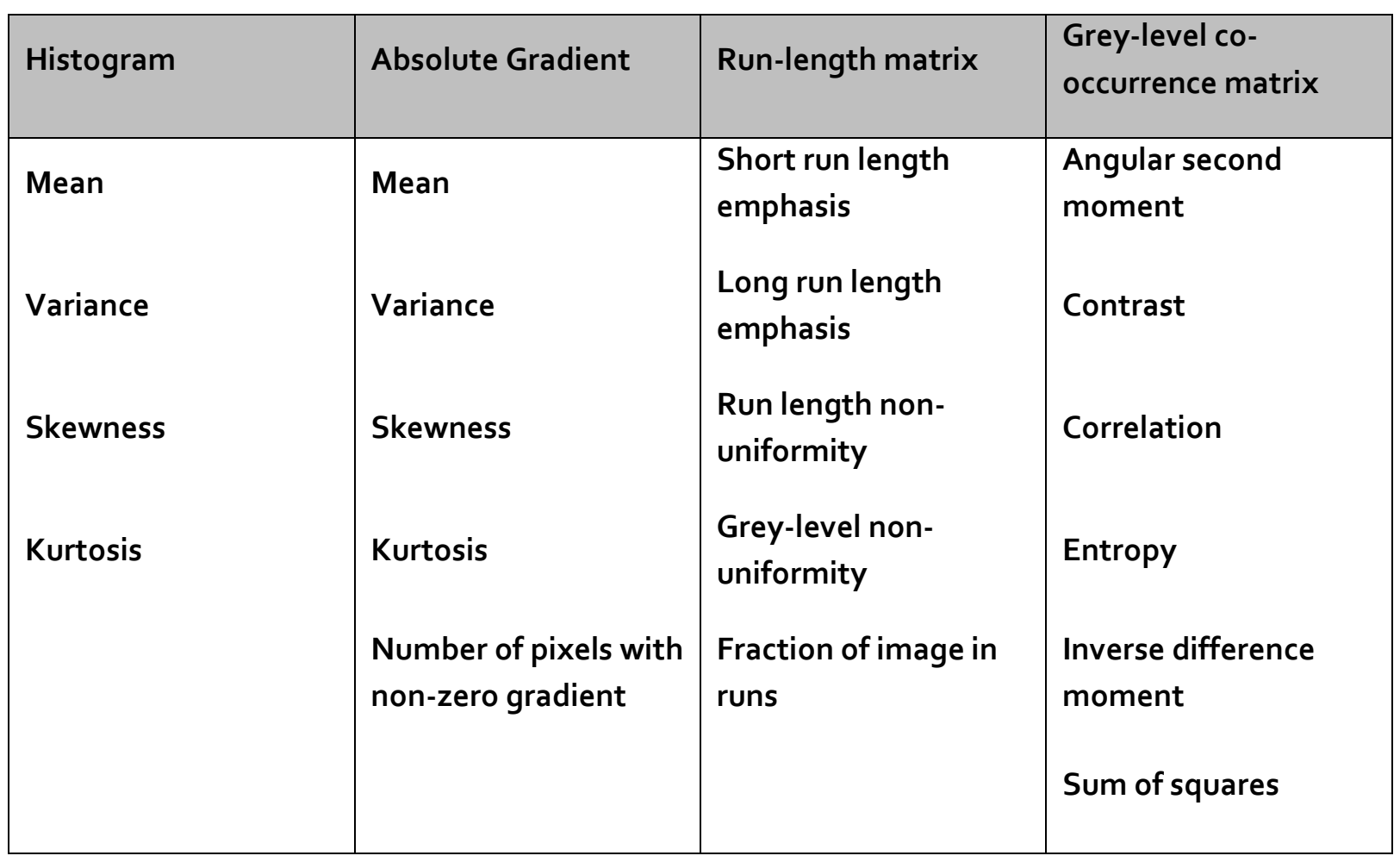

TABLE 2

Baseline characteristics of study subjects

\begin{tabular}{|c|c|c|c|}
\hline & Group 1 & Group 2 & Group 3 \\
\hline $\mathrm{Age}^{\mathrm{a}}$ & $26.2(21-29)$ & $46.7(42-50)$ & $71.4(57-84)$ \\
\hline Body mass index $\left(\mathrm{kg} / \mathrm{m}^{2}\right)^{a}$ & $24.1(3.3)$ & $27 \cdot 3(4 \cdot 3)$ & $31.3(4.9)$ \\
\hline Females/males & $4 / 6$ & $3 / 7$ & $7 / 3$ \\
\hline Right knee/Left knee & $5 / 5$ & $7 / 3$ & $6 / 4$ \\
\hline Oxford knee score ${ }^{a}$ & $48(0)$ & $28.1(8.3)$ & $17.4(4.4)$ \\
\hline Kellgren-Lawrence grade $0 / 1 / 2 / 3 / 4$ & $\mathrm{~N} / \mathrm{A}$ & $4 / 6 / 0 / 0 / 0$ & $0 / 0 / 1 / 5 / 4$ \\
\hline
\end{tabular}

${ }^{a}$ values are mean (standard deviation) except age which is mean (range) 
TABLE 3

Results for texture parameters at the medial tibial plateau. Significant differences are highlighted in bold. Parameters demonstrating significant differences between groups are highlighted with asterisks (*).

\begin{tabular}{|c|c|c|c|c|c|c|c|}
\hline Parameter & $\begin{array}{l}\text { Group } \\
1\end{array}$ & $\begin{array}{l}\text { Group } \\
2\end{array}$ & $\begin{array}{l}\text { Group } \\
3\end{array}$ & $\begin{array}{l}p \text { (all } \\
\text { groups) }\end{array}$ & $\begin{array}{l}p \text { (group } \\
1 / \text { group 2) }\end{array}$ & $\begin{array}{l}p \text { (group } \\
2 / \text { group } 3 \text { ) }\end{array}$ & $\begin{array}{l}p \text { (group } \\
\text { 1/group 3) }\end{array}$ \\
\hline \multicolumn{8}{|l|}{ Histogram } \\
\hline Mean* & $\begin{array}{l}1938 \\
(298) \\
\end{array}$ & $\begin{array}{l}2113 \\
(202) \\
\end{array}$ & $\begin{array}{l}2192 \\
(487) \\
\end{array}$ & $<0.001$ & 0.02 & 0.643 & $<0.001$ \\
\hline Variance* & $\begin{array}{l}326921 \\
(105500)\end{array}$ & $\begin{array}{l}432043 \\
(152646) \\
\end{array}$ & $\begin{array}{l}527767 \\
(265781) \\
\end{array}$ & $<0.001$ & 0.007 & 0.017 & $<0.001$ \\
\hline Skewness* & $\begin{array}{l}-0.48 \\
(0.28) \\
\end{array}$ & $\begin{array}{l}-0.62 \\
(0.28) \\
\end{array}$ & $\begin{array}{l}-0.75 \\
(0.34) \\
\end{array}$ & $<0.001$ & 0.046 & 0.050 & $<0.001$ \\
\hline Kurtosis & $\begin{array}{l}0.10 \\
(0.58)\end{array}$ & $\begin{array}{l}0.33 \\
(0.57) \\
\end{array}$ & $\begin{array}{l}0.42 \\
(1.21) \\
\end{array}$ & 0.101 & 0.420 & 0.113 & $>0.99$ \\
\hline \multicolumn{8}{|l|}{ Absolute gradient } \\
\hline Mean* & $\begin{array}{l}1.26 \\
(0.28) \\
\end{array}$ & $\begin{array}{l}1.19 \\
(0.18) \\
\end{array}$ & $\begin{array}{l}0.97 \\
(0.27) \\
\end{array}$ & $<0.001$ & 0.339 & $<0.001$ & $<0.001$ \\
\hline Variance* & $\begin{array}{l}0.65 \\
(0.24) \\
\end{array}$ & $0.61(0.1)$ & $\begin{array}{l}0.48 \\
(0.11) \\
\end{array}$ & $<0.001$ & 0.614 & $<0.001$ & $<0.001$ \\
\hline Skewness* & $\begin{array}{l}0.39 \\
(0.22) \\
\end{array}$ & $\begin{array}{l}0.47 \\
(0.19) \\
\end{array}$ & $\begin{array}{l}0.28 \\
(0.17) \\
\end{array}$ & $<0.001$ & 0.096 & $<0.001$ & 0.008 \\
\hline Kurtosis* & $\begin{array}{l}0.57 \\
(0.66) \\
\end{array}$ & $\begin{array}{l}0.88 \\
(0.84) \\
\end{array}$ & $\begin{array}{l}-0.04 \\
(0.91) \\
\end{array}$ & $<0.001$ & 0.110 & $<0.001$ & $<0.001$ \\
\hline $\begin{array}{r}\text { Number of pixels with non- } \\
\text { zero gradient* }\end{array}$ & $0.83(.07)$ & $0.81(.07)$ & $\begin{array}{l}0.72 \\
(0.14) \\
\end{array}$ & $<0.001$ & $>0.99$ & $<0.001$ & $<0.001$ \\
\hline \multicolumn{8}{|l|}{ Run-length matrix } \\
\hline Short run length emphasis* & $\begin{array}{l}0.9 \\
(0.03) \\
\end{array}$ & $\begin{array}{l}0.9 \\
(0.02) \\
\end{array}$ & $\begin{array}{l}0.87 \\
(0.04) \\
\end{array}$ & $<0.001$ & 0.960 & $<0.001$ & $<0.001$ \\
\hline Long run length emphasis* & $\begin{array}{l}1.51 \\
(0.21) \\
\end{array}$ & $\begin{array}{l}1.55 \\
(0.15) \\
\end{array}$ & $\begin{array}{l}1.79 \\
(0.38) \\
\end{array}$ & $<0.001$ & $>0.99$ & $<0.001$ & $<0.001$ \\
\hline Run length non-uniformity* & $\begin{array}{l}2999 \\
(615) \\
\end{array}$ & $\begin{array}{l}3964 \\
(656) \\
\end{array}$ & $\begin{array}{l}4356 \\
(1163) \\
\end{array}$ & $<0.001$ & $<0.001$ & 0.036 & $<0.001$ \\
\hline Grey-level non-uniformity* & $\begin{array}{l}265.4 \\
(59.7) \\
\end{array}$ & $\begin{array}{l}348.7 \\
(84.1) \\
\end{array}$ & $\begin{array}{l}527.4 \\
(195.7) \\
\end{array}$ & $<0.001$ & 0.001 & $<0.001$ & $<0.001$ \\
\hline Fraction of image in runs* & $\begin{array}{l}0.87 \\
(0.03)\end{array}$ & $\begin{array}{l}0.86 \\
(0.03)\end{array}$ & $\begin{array}{l}0.83 \\
(0.06)\end{array}$ & $<0.001$ & 0.862 & $<0.001$ & $<0.001$ \\
\hline \multicolumn{8}{|c|}{ Grey-level co-occurrence matrix } \\
\hline Angular second moment* & $\begin{array}{l}0.0076 \\
(0.005) \\
\end{array}$ & $\begin{array}{l}0.0073 \\
(0.003)\end{array}$ & $\begin{array}{l}0.014 \\
(0.01) \\
\end{array}$ & $<0.001$ & $>0.99$ & $<0.001$ & $<0.001$ \\
\hline Contrast* & $17 \cdot 3(9 \cdot 3)$ & $15.5(4.1)$ & $\begin{array}{l}10.4 \\
(4.9) \\
\end{array}$ & $<0.001$ & 0.386 & $<0.001$ & $<0.001$ \\
\hline Correlation* & $\begin{array}{l}0.55 \\
(0.09) \\
\end{array}$ & $\begin{array}{l}0.62 \\
(0.11) \\
\end{array}$ & $\begin{array}{l}0.64 \\
(0.12) \\
\end{array}$ & $<0.001$ & 0.004 & 0.496 & $<0.001$ \\
\hline Entropy* & $\begin{array}{l}2.33 \\
(0.21) \\
\end{array}$ & $\begin{array}{l}2.34 \\
(0.17) \\
\end{array}$ & $\begin{array}{l}2.13 \\
(0.28) \\
\end{array}$ & $<0.001$ & $>0.99$ & $<0.001$ & $<0.001$ \\
\hline Inverse difference moment* & $\begin{array}{l}0.28 \\
(0.06) \\
\end{array}$ & $\begin{array}{l}0.29 \\
(0.04) \\
\end{array}$ & $\begin{array}{l}0.35 \\
(0.08) \\
\end{array}$ & $<0.001$ & $>0.99$ & $<0.001$ & $<0.001$ \\
\hline Sum of squares & $\begin{array}{l}19.9 \\
(11.1) \\
\end{array}$ & $\begin{array}{l}22.4 \\
(10.2) \\
\end{array}$ & $\begin{array}{l}16.6 \\
(10.2) \\
\end{array}$ & 0.012 & 0.574 & 0.009 & 0.275 \\
\hline \multicolumn{8}{|l|}{ Cartilage mapping } \\
\hline$T 2$ & $39.0(5.1)$ & $40.6(7.1)$ & $\mathrm{N} / \mathrm{A}$ & N/A & 0.125 & N/A & $\mathrm{N} / \mathrm{A}$ \\
\hline
\end{tabular}


TABLE 4

Results for texture parameters at the lateral tibial plateau. Significant differences are highlighted in bold. Parameters demonstrating significant differences between groups are highlighted with asterisks (*).

\begin{tabular}{|c|c|c|c|c|c|c|c|}
\hline Parameter & $\begin{array}{l}\text { Group } \\
1\end{array}$ & $\begin{array}{l}\text { Group } \\
2\end{array}$ & $\begin{array}{l}\text { Group } \\
3\end{array}$ & $\begin{array}{l}p \text { (all } \\
\text { groups) }\end{array}$ & $\begin{array}{l}p \text { (group } \\
1 / \text { group 2) }\end{array}$ & $\begin{array}{l}p \text { (group } \\
2 / \text { group 3) }\end{array}$ & $\begin{array}{l}p \text { (group } \\
1 \text { group 3) }\end{array}$ \\
\hline \multicolumn{8}{|l|}{ Histogram } \\
\hline Mean* & $\begin{array}{l}2357 \\
(380) \\
\end{array}$ & $\begin{array}{l}2528 \\
(268) \\
\end{array}$ & $\begin{array}{l}3092 \\
(785) \\
\end{array}$ & $<0.001$ & 0.235 & $<0.001$ & $<0.001$ \\
\hline Variance* $^{*}$ & $\begin{array}{l}434757 \\
(192780) \\
\end{array}$ & $\begin{array}{l}433517 \\
(110324)\end{array}$ & $\begin{array}{l}749430 \\
(506768)\end{array}$ & $<0.001$ & $>0.99$ & $<0.001$ & $<0.001$ \\
\hline Skewness* & $\begin{array}{l}-0.134 \\
(0.26) \\
\end{array}$ & $\begin{array}{l}0.384 \\
(0.32) \\
\end{array}$ & $\begin{array}{l}-0.340 \\
(0.37) \\
\end{array}$ & $<0.001$ & $<0.001$ & $>0.99$ & 0.002 \\
\hline Kurtosis* & $\begin{array}{l}0.41 \\
(0.43)\end{array}$ & $\begin{array}{l}0.83 \\
(0.07)\end{array}$ & $\begin{array}{l}1.04 \\
(1.00) \\
\end{array}$ & $<0.001$ & 0.003 & 0.328 & $<0.001$ \\
\hline \multicolumn{8}{|l|}{ Absolute gradient } \\
\hline Mean* & $\begin{array}{l}1.31 \\
(0.31) \\
\end{array}$ & $\begin{array}{l}1.27 \\
(0.22) \\
\end{array}$ & $\begin{array}{l}1.10 \\
(0.31) \\
\end{array}$ & $<0.001$ & $>0.99$ & 0.006 & $<0.001$ \\
\hline Variance & $\begin{array}{l}0.71 \\
(0.29)\end{array}$ & $\begin{array}{l}0.65 \\
(0.13)\end{array}$ & $\begin{array}{l}0.60 \\
(0.19)\end{array}$ & 0.037 & 0.526 & 0.662 & 0.031 \\
\hline Skewness & $\begin{array}{l}0.52 \\
(0.27) \\
\end{array}$ & $\begin{array}{l}0.51 \\
(0.20)\end{array}$ & $\begin{array}{l}0.64 \\
(0.44) \\
\end{array}$ & 0.035 & $>0.99$ & 0.087 & 0.064 \\
\hline Kurtosis & $\begin{array}{l}1.10 \\
(1.05) \\
\end{array}$ & $\begin{array}{l}1.00 \\
(0.88) \\
\end{array}$ & $\begin{array}{l}1.71 \\
(2.23) \\
\end{array}$ & 0.022 & $>0.99$ & 0.084 & 0.031 \\
\hline $\begin{array}{r}\text { Number of pixels with non- } \\
\text { zero gradient* }\end{array}$ & $\begin{array}{l}0.83 \\
(0.08)\end{array}$ & $\begin{array}{l}0.83 \\
(0.08)\end{array}$ & $\begin{array}{l}0.77 \\
(0.13)\end{array}$ & $<0.001$ & $>0.99$ & 0.001 & 0.002 \\
\hline \multicolumn{8}{|l|}{ Run-length matrix } \\
\hline Short run length emphasis* & $\begin{array}{l}0.91 \\
(0.02)\end{array}$ & $\begin{array}{l}0.91 \\
(0.02)\end{array}$ & $\begin{array}{l}0.89 \\
(0.04)\end{array}$ & $<0.001$ & $>0.99$ & $<0.001$ & $<0.001$ \\
\hline Long run length emphasis* & $\begin{array}{l}1.46 \\
(0.16)\end{array}$ & $\begin{array}{l}1.48 \\
(0.16)\end{array}$ & $\begin{array}{l}1.62 \\
(0.27)\end{array}$ & $<0.001$ & $>0.99$ & $<0.001$ & $<0.001$ \\
\hline Run length non-uniformity* & $\begin{array}{l}3569 \\
(947)\end{array}$ & $\begin{array}{l}4311 \\
(719) \\
\end{array}$ & $\begin{array}{l}4547 \\
(1292) \\
\end{array}$ & $<0.001$ & $<0.001$ & 0.608 & $<0.001$ \\
\hline Grey-level non-uniformity* & $\begin{array}{l}276.8 \\
(75.0)\end{array}$ & $\begin{array}{l}362.2 \\
(92.3)\end{array}$ & $\begin{array}{l}432.6 \\
(132.0)\end{array}$ & $<0.001$ & $<0.001$ & 0.001 & $<0.001$ \\
\hline Fraction of image in runs* & $\begin{array}{l}0.88 \\
(0.03)\end{array}$ & $\begin{array}{l}0.88 \\
(0.03)\end{array}$ & $\begin{array}{l}0.85 \\
(0.05)\end{array}$ & $<0.001$ & $>0.99$ & $<0.001$ & $<0.001$ \\
\hline \multicolumn{8}{|c|}{ Grey-level co-occurrence matrix } \\
\hline Angular second moment & $\begin{array}{l}0.0065 \\
(0.0044) \\
\end{array}$ & $\begin{array}{l}0.0070 \\
(0.0042)\end{array}$ & $\begin{array}{l}0.0094 \\
(0.0066) \\
\end{array}$ & 0.005 & $>0.99$ & 0.030 & 0.007 \\
\hline Contrast & $\begin{array}{l}19.2 \\
(10.7) \\
\end{array}$ & $17.0(5.2)$ & $14.6(7.4)$ & 0.008 & 0.387 & 0.323 & 0.006 \\
\hline Correlation & $\begin{array}{l}0.61 \\
(0.08) \\
\end{array}$ & $\begin{array}{l}0.60 \\
(0.10)\end{array}$ & $\begin{array}{l}0.63 \\
(0.11)\end{array}$ & 0.325 & $>0.99$ & 0.473 & 0.765 \\
\hline Entropy & $\begin{array}{l}2.42 \\
(0.22) \\
\end{array}$ & $\begin{array}{l}2.38 \\
(0.19) \\
\end{array}$ & $\begin{array}{l}2.28 \\
(0.25) \\
\end{array}$ & 0.003 & $>0.99$ & 0.043 & 0.003 \\
\hline Inverse difference moment* & $\begin{array}{l}0.27 \\
(0.05) \\
\end{array}$ & $\begin{array}{l}0.28 \\
(0.05)\end{array}$ & $\begin{array}{l}0.32 \\
(0.07) \\
\end{array}$ & $<0.001$ & $>0.99$ & 0.001 & $<0.001$ \\
\hline Sum of squares & $\begin{array}{l}26.0 \\
(15.1) \\
\end{array}$ & $\begin{array}{l}22.6 \\
(8.2) \\
\end{array}$ & $\begin{array}{l}20.7 \\
(11.3) \\
\end{array}$ & 0.048 & 0.36 & $>0.99$ & 0.045 \\
\hline \multicolumn{8}{|l|}{ Cartilage mapping } \\
\hline$T 2$ & $33.1(4.5)$ & $\begin{array}{l}34.8 \\
(4.9)\end{array}$ & N/A & $\mathrm{N} / \mathrm{A}$ & 0.056 & N/A & $\mathrm{N} / \mathrm{A}$ \\
\hline
\end{tabular}


TABLE 5

Results of Bland-Altman reliability analysis for each calculated texture parameter.

\begin{tabular}{|c|c|c|}
\hline Parameter & $\begin{array}{c}\text { Mean bias } \\
\text { (95\% limits of agreement) }\end{array}$ & Mean value \\
\hline \multicolumn{3}{|l|}{ Histogram } \\
\hline Mean & $-24.5(-207.8-158.5)$ & 2312.8 \\
\hline Variance & $19607(-185114-224329)$ & 432948.2 \\
\hline Skewness & $-0.1(-0.6-0.3)$ & -0.3 \\
\hline Kurtosis & $0.2(-0.6-0.9)$ & 0.3 \\
\hline \multicolumn{3}{|l|}{ Absolute gradient } \\
\hline Mean & $-0.006(-0.08-0.07)$ & 1.25 \\
\hline Variance & $-0.002(-0.10-0.10)$ & 0.65 \\
\hline Skewness & $-0.02(-0.3-0.3)$ & 0.5 \\
\hline Kurtosis & $-0.1(-1.5-1.3)$ & 0.9 \\
\hline Number of pixels with non-zero gradient & $-0.003(-0.02-0.02)$ & 0.8 \\
\hline \multicolumn{3}{|l|}{ Run-length matrix } \\
\hline Short run length emphasis & $-0.001(-0.008-0.006)$ & 0.90 \\
\hline Long run length emphasis & $0.009(-0.04-0.06)$ & 1.50 \\
\hline Run length non-uniformity & $-27(-2140-2085)$ & 3858 \\
\hline Grey-level non-uniformity & $-1.6(-210-207)$ & 330 \\
\hline Fraction of image in runs & $-0.002(-0.01-0.01)$ & 0.87 \\
\hline \multicolumn{3}{|l|}{ Grey-level co-occurrence matrix } \\
\hline Angular second moment & $0.0001(-0.002-0.002)$ & 0.007 \\
\hline Contrast & $0.03(-3.4-3.5)$ & 16.9 \\
\hline Correlation & $0.02(-0.10-0.13)$ & 0.59 \\
\hline Entropy & $0.002(-0.09-0.09)$ & 2.36 \\
\hline Inverse difference moment & $0.001(-0.01-0.02)$ & 0.29 \\
\hline Sum of squares & $1.3(-8.2-10.7)$ & 21.8 \\
\hline
\end{tabular}




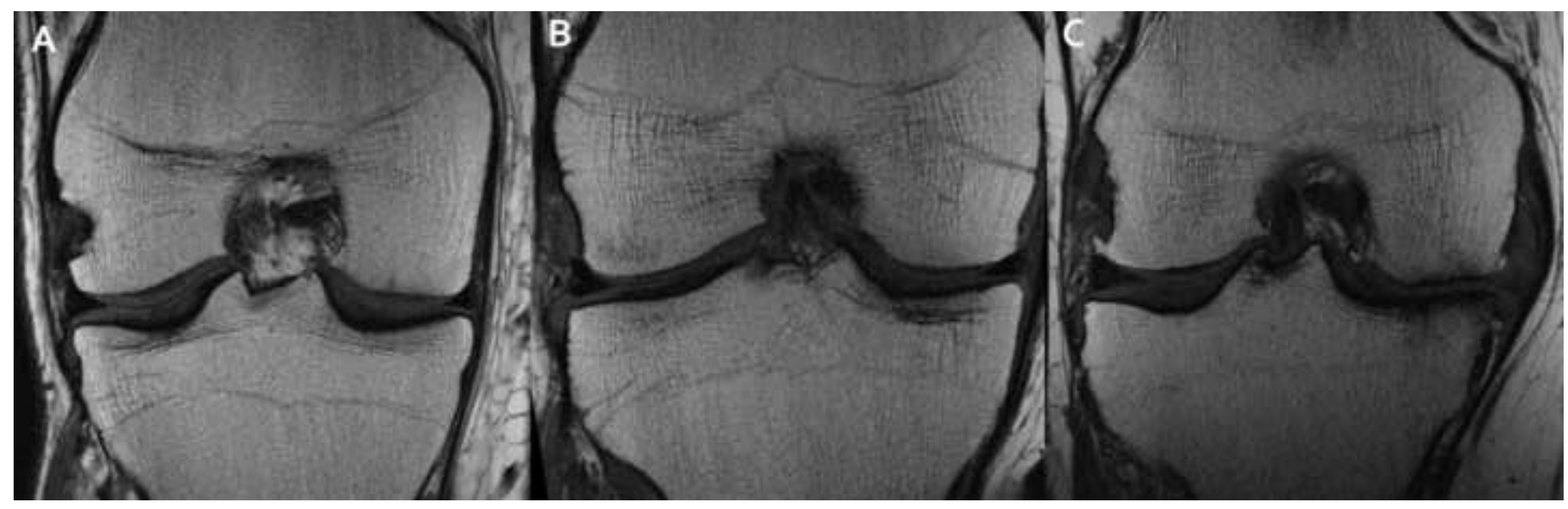



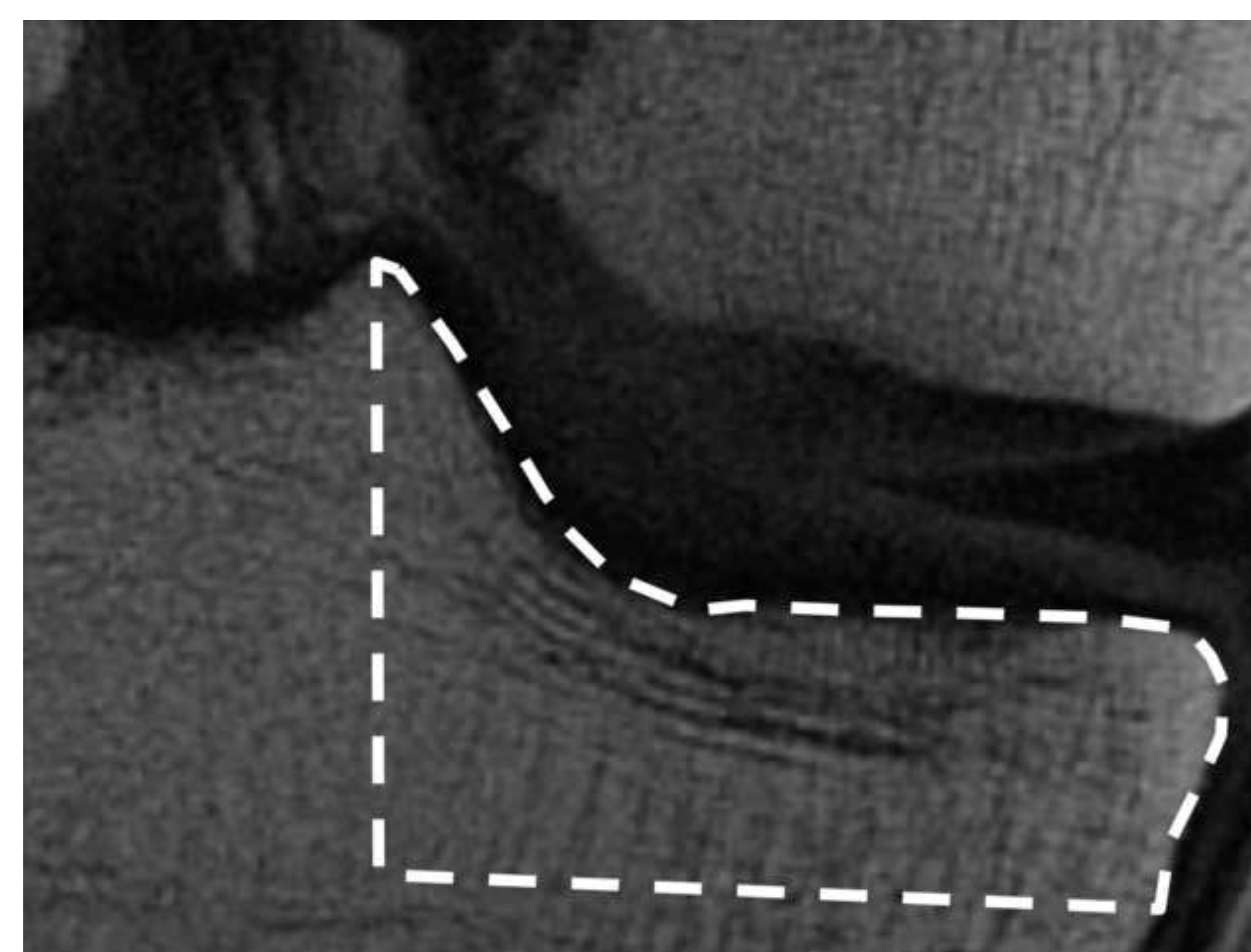

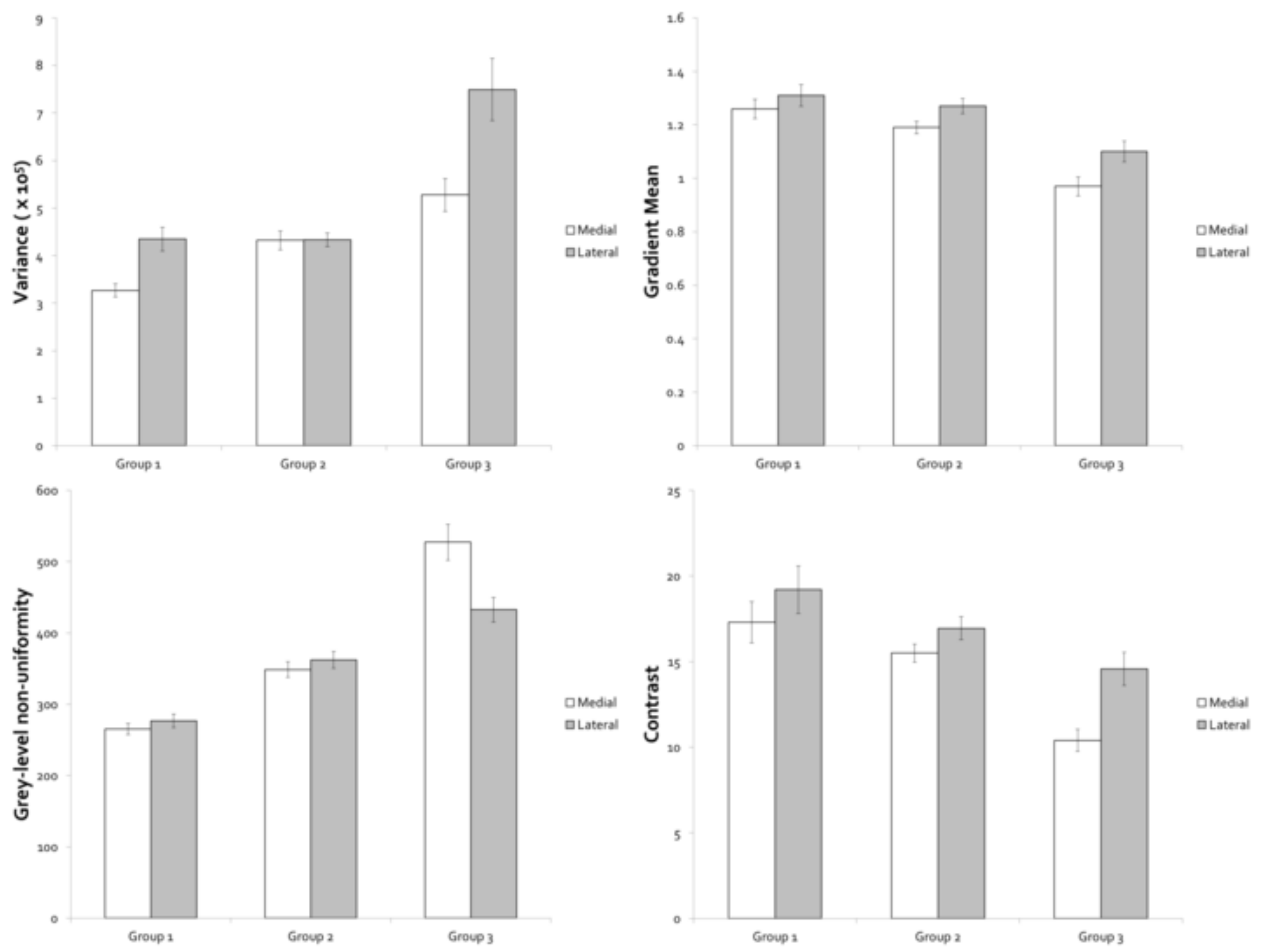

OMedial

口Lateral

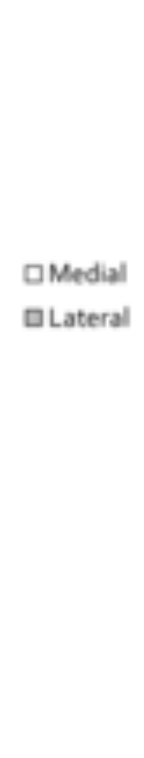



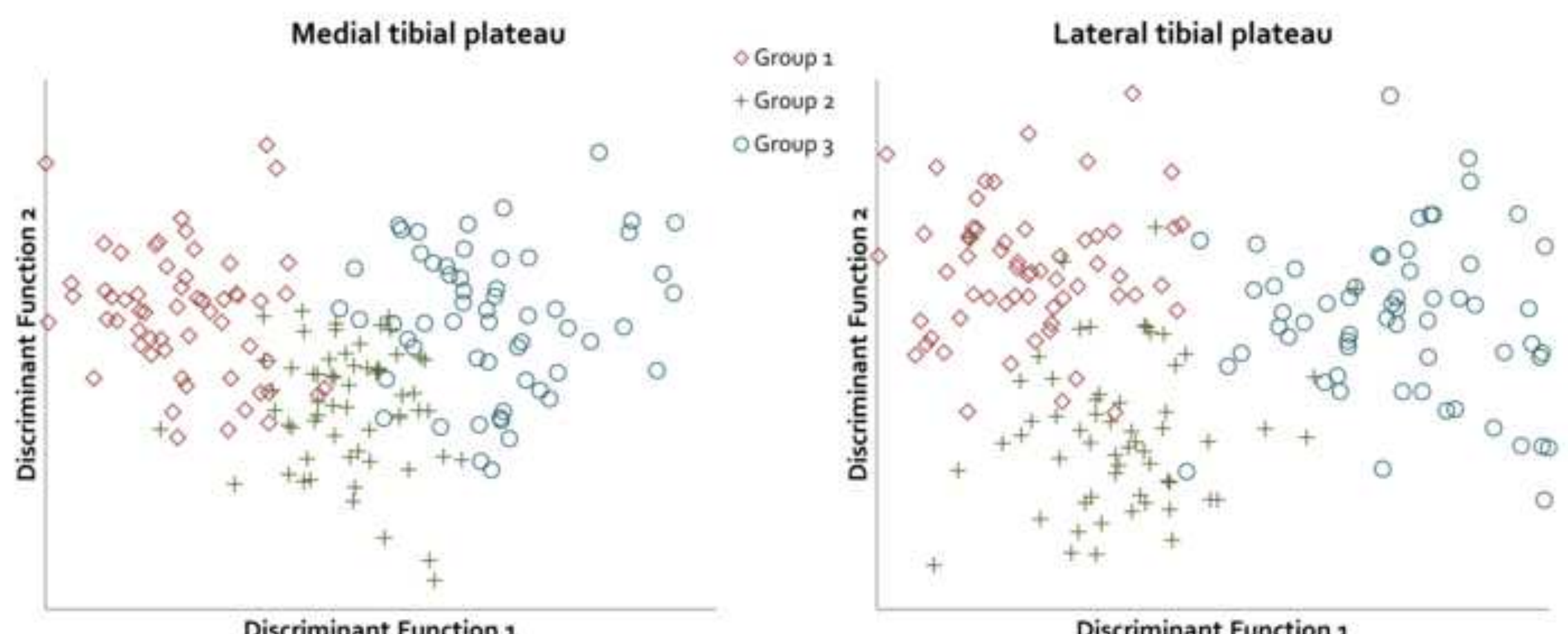

Discriminant Function 1

Discriminant Function 1 


\section{Medial tibial plateau}

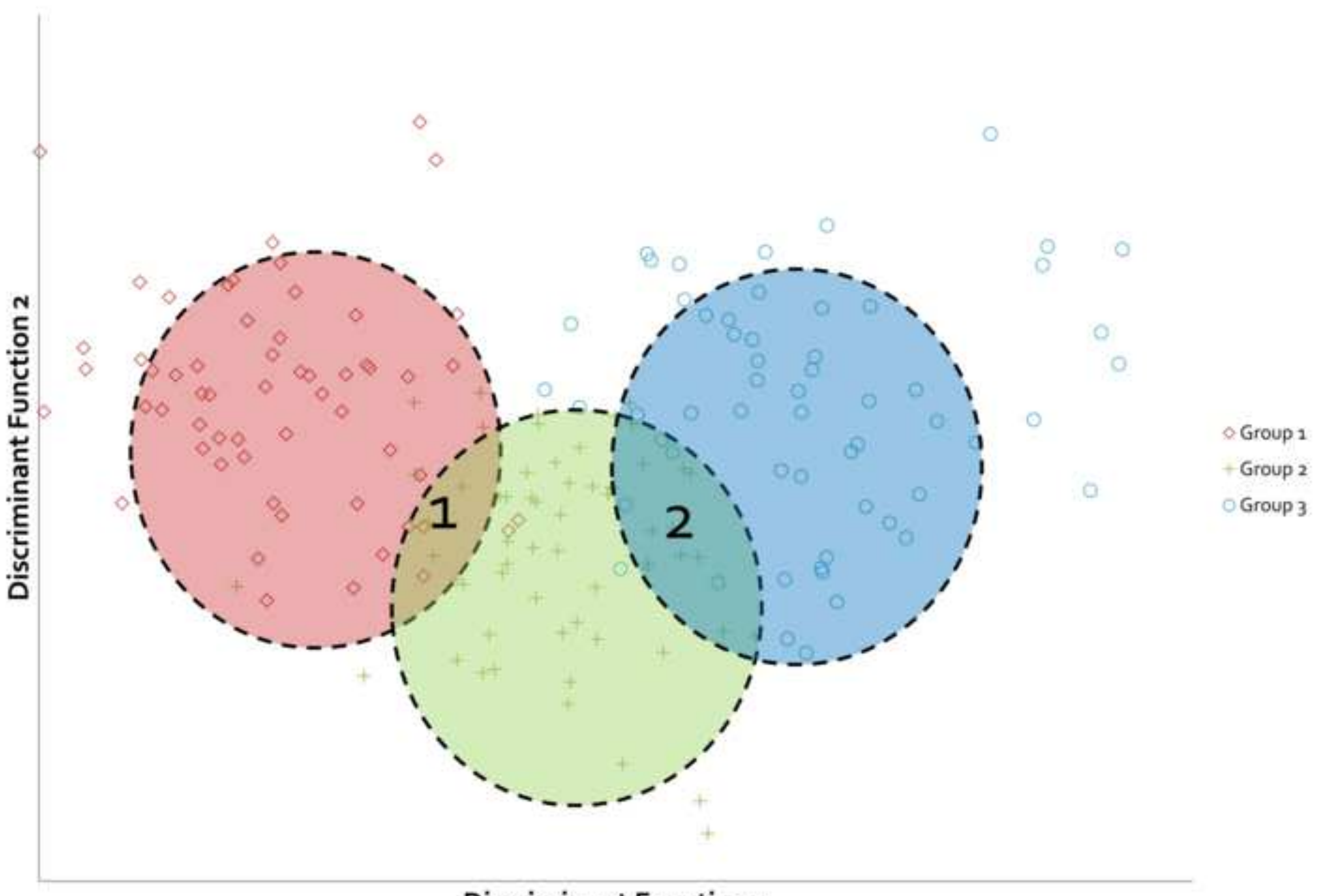




\section{Histogram Mean}

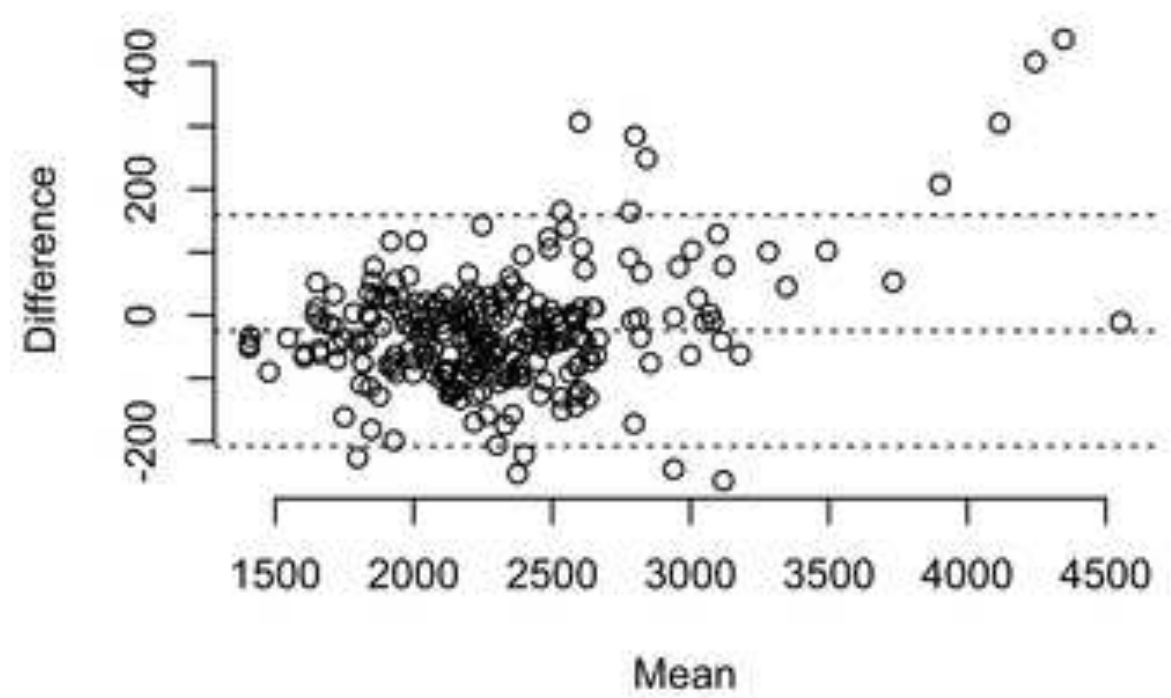

Grey-Level Non-Uniformity

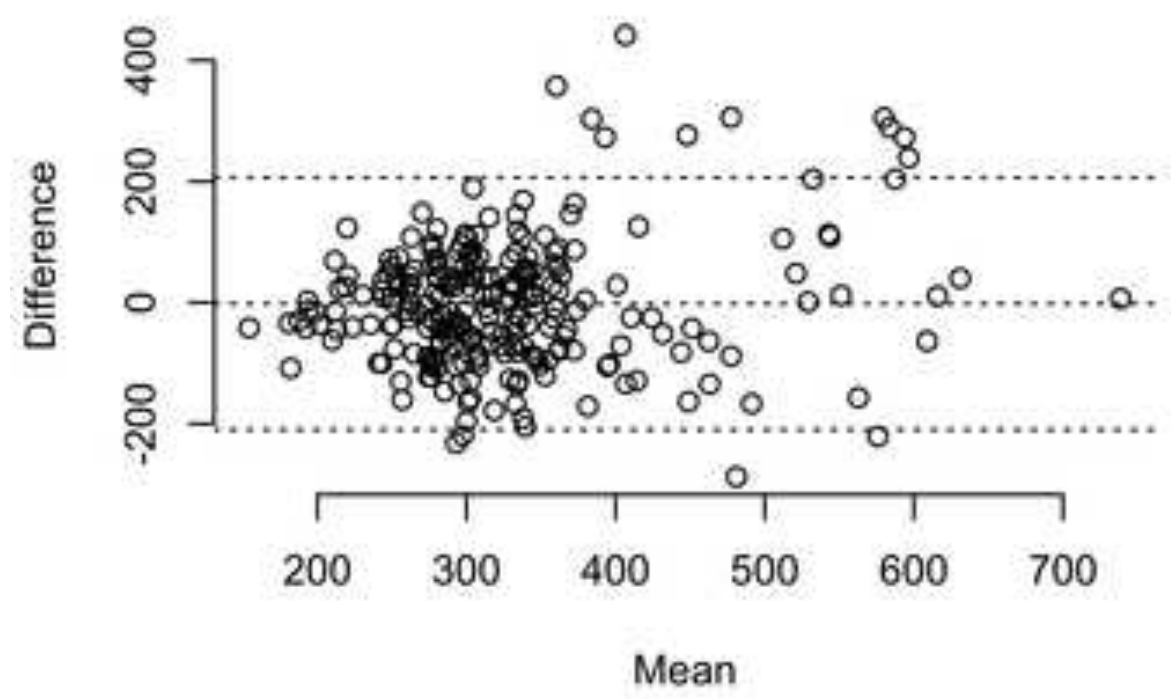

\section{Gradient Mean}

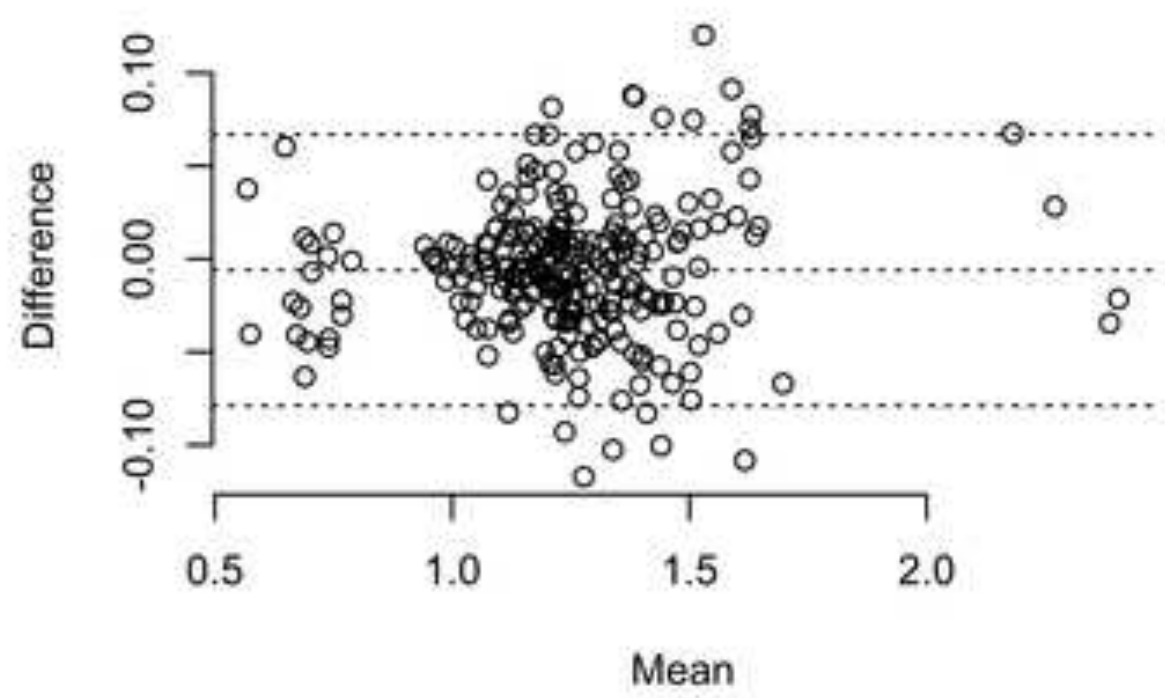

Contrast

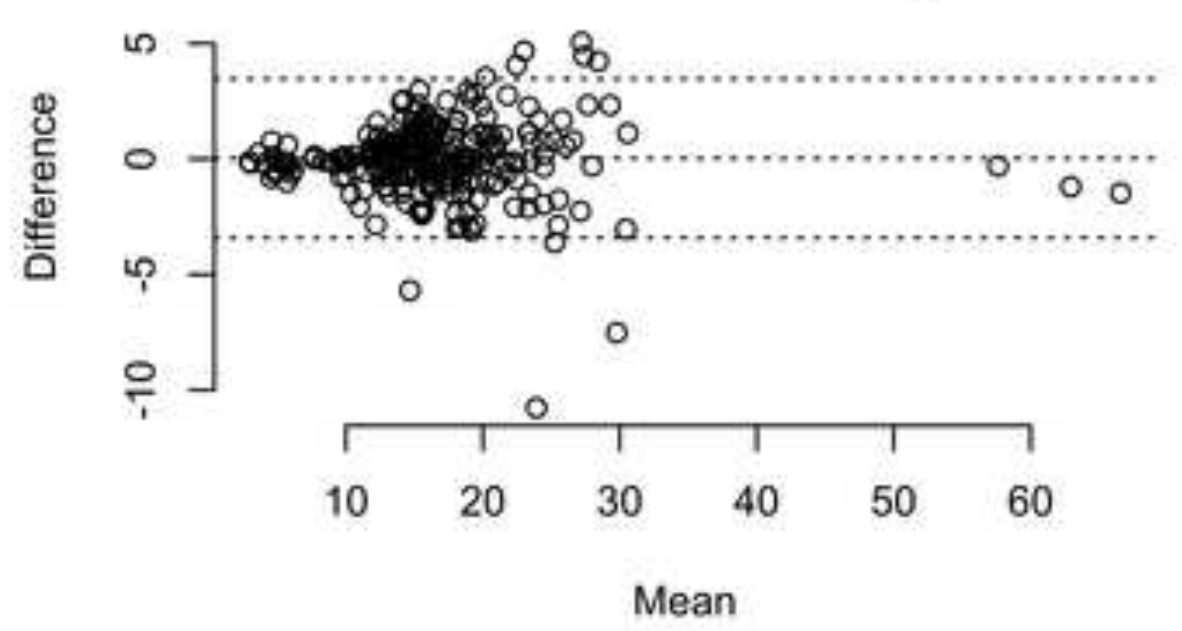




\section{ACKNOWLEDGEMENTS}

This study was funded by the Royal College of Radiologists Pump Priming Grant scheme. The research team acknowledge the support of the National Institute for Health Research, through the Comprehensive Clinical Research Network. We would like to thank Angela Bullough and Sue Butters, Orthopaedic Research Nurses, for their assistance with participant screening and recruitment. 